\title{
PROBLEMS OF COOPERATIVE INTELLIGENT TRANSPORT SYSTEMS (ITS) IMPLEMENTATION IN EUROPEAN UNION
}

\author{
Gabriel Nowacki \\ Motor Transport Institute \\ Transport Management \& Telematics Centre \\ Jagiellońska Street 80, 03-301 Warsaw, Poland \\ tel.: +48 224385134, fax: +48228110906 \\ e-mail: gabriel.nowacki@its.waw.pl
}

\begin{abstract}
The paper presents implementation problems of Co-opeartive Intelligent Transport System (ITS) in Member States of European Union. ITS means systems in which information and communication technologies are applied in the field of road transport, including infrastructure, vehicles and users, and in traffic management and mobility management, as well as for interfaces with other modes of transport. Interoperability of ITS is the capacity of systems and the underlying business processes to exchange data and to share information and knowledge. ITS application means an operational instrument for the application of ITS. ITS service is the provision of an ITS application through a well-defined organisational and operational framework with the aim of contributing to the user safety, efficiency, comfort and/or to facilitate or support transport and travel operations. According to the European Commission the autonomous intelligent transport systems implemented in Member States of European Union are not interoperable due to some reasons, for instance discrepancies in the interpretation of laws, technology standards (specifications), especially lack of cooperation capability. European Commission has taken steps in mentioned issue (directive 2010/40/EU, mandate M/453, decision 2011/453/EU). The author has presented synthetically problems in mentioned area and determined resolutions of them on level of European Union and Poland. Furthermore the main results of research projects: The National Automatic Toll Collection System (NATCS) and Methodic of eCall automatically informing system of traffic accidents developed by Motor Transport Institute.
\end{abstract}

Keywords: intelligent transport systems (ITS), mandate M/453, directive 2010/40/UE, interoperability

\section{Introduction}

According to the World Health Organisation in 20 years time, road accidents will take fifth place on the list of the most frequent causes of death in the world. It has been estimated that annual costs of accidents in Europe amount to 130 billion Euros, while in Poland itself - 5 billion Euros. Despite the measures taken to reduce this amount, the number of fatal road accidents' victims is in the European Union exceptionally high - 34800 in 2009 [5].

The reason for such situation is a significant growth of the road transport, associated with the development of the European economy and citizens demands as far as mobility is concerned, which results in ever-growing congestion of the road infrastructure, energy consumption increase as well as ecological and social problems.

All EU countries devote more and more attention to the road safety. An ambitious objective has been designated to lower, by a half, the number of fatal road accidents' victims, however in order to achieve it, it is necessary to have systematic actions taken.

European action program for the road traffic safety defines main areas of the activities: promoting more responsible attitudes of the drivers (obeying road traffic regulations and punishing dangerous behaviour on the roads), improving safety of the vehicles by introducing new technical solutions, improving road infrastructure, thanks to the information and communication technology. 
The subsequent planned initiatives envisage gathering and analysing data on the injuries sustained in the road accidents and studying optimal solutions in this matter. For those initiatives to become successful, the stake-holders (member states, regional and local authorities, industry, transport firms, and private users) ought to be responsible together to ensure the road safety. The plan of action contains proposal for all interested parties to sign European Road Traffic Safety Chart.

The statistical data suggests that the year 2010 was the safest in the last 20 years (Fig. 1) on the Polish roads (lowest number of the people killed). Despite this fact, in the statistics referring to the percentage decrease of the number of accidents in the last decade (2001-2010), we still hold one of the last places. For this period, an average percentage decrease of the number of accidents in the EU was 43\%, while in Poland - 29\%, in Lithuania and Estonia - 61\% and in Latvia $-58 \%$. European Commission regularly publishes reports on the safety on the roads of all countries belonging to the EU. The statistics are invariably devastating for Poland, which with respect to the number of victims and mortality in the road accidents is always at the end of the list. The threat of death in the road accident in Poland is three times higher than in the rest of the EU countries, and the statistics of the fatalities per 100 accidents we are worse even than in Lithuania. For Poland, this number is 10.3 , in Lithuania 9.9, Greece -8.8 , while the average in the EU is 3. In this context, a shockingly low mortality coefficient is noted in such countries as Germany and Great Britain (1.4), as well as in Austria (1.7) or Italy and Sweden (1.9). The probability of death of the accident participant is in Poland, on average, four times higher.

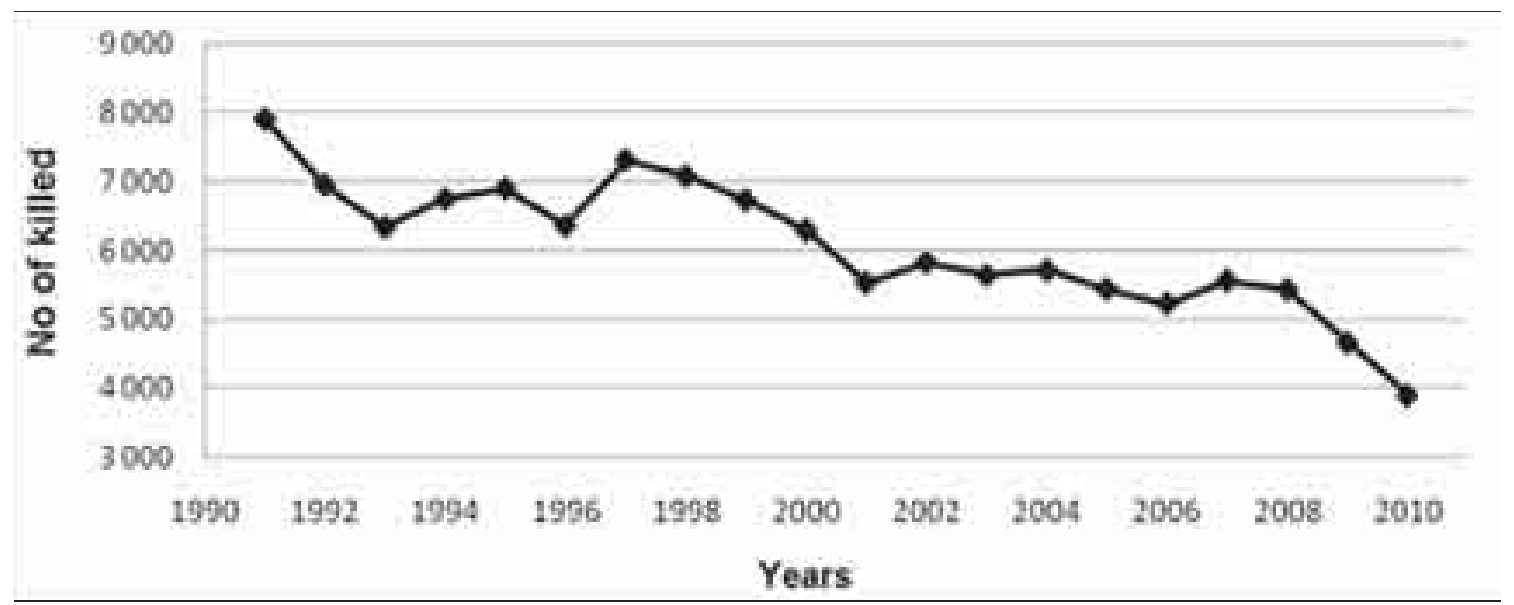

Fig. 1. Number of people killed on the roads during the years 1991-2010

Moreover, in the statistics concerning the number of people killed per 1 million inhabitants we also hold one of the last places, since the EU average in 2010 was 61, while in Poland - 102, and worse are only Romania - 111 and Greece - 112 .

Data of the National Police Headquarters [10] shows, that in 2011 there were 40065 accidents (38 776 - 2010) on the Polish roads, as the result of which 4189 (3907 - 2010) people died and 49 501 (48 872 - 2010) people were injured. In comparison to 2010 there was an increase of the number of accidents by 1233 , i.e. by $+3.2 \%$, increase of the number of fatalities by 282 people, i.e. by $+7.2 \%$, and increase of the number of people injured by 549 , i.e. by $+1.1 \%$.

In Poland, accidents are regarded at present as one of the largest public health problems. More so, their consequence is not only a trauma of the injured ones and their families but also a significant burden to the public finances.

The European Commission has taken actions, turning attention to the implementation of the intelligent transport systems (ITS), which have a direct influence on the road traffic safety and reduction of the road congestion.

Intelligent transport systems (ITS) are the systems, in which information and communication 
technologies are used in the area of the road transport, covering infrastructure vehicles and users, as well as traffic and mobility management, and interfaces with other types of transport.

The studies show, that the benefits stemming from the application of ITS are very large [5], and these systems cause, among the others:

- increase in the throughput of the transport infrastructure by an average $22.5 \%$,

- improvement of the road traffic safety (significant decrease of the number of accidents by $60 \%$ in the none-built up area and 50\% in the built up area),

- substantial shortening of the travelling time and energy consumption (by about $60 \%$ ),

- improving quality of the natural environment (reduction in the exhaust emission by an average $40 \%$,

- improvement of the comfort of travelling and traffic conditions as well as that of the people using public transport and pedestrians,

- reduction in the cost of managing road vehicles fleet, costs associated with maintaining and renewing road surfaces (reductions in the expenditures on the transport infrastructure even by $30-35 \%)$.

In some member states, the ITS applications are already being implemented in the road transport sector. This implementation however remains fragmented and uncoordinated and thus it can not ensure geographical continuity of the ITS services in the entire EU and at its external boarders.

In order to ensure coordinated and effective implementation of ITS in the area of the entire EU, it is necessary to introduce specifications, including - in the appropriate cases - standards defining detailed regulations and procedures. During further implementation of ITS, it is necessary to take into account existing ITS infrastructure created by a given member state, as far as technical progress and sustained financial expenditures, are concerned. In the appropriate cases, specifications should cover detailed regulations defining procedures of evaluating conformity or the usefulness to utilise the component parts.

ITS systems will be effective only when they are designed, maintaining definite standards and requirements, because they affect directly safety of the traffic participants.

\section{European Commission's actions on the implementation of the integrated ITS}

The European Commission on the 16 of December 2008 published the Announcement - Plan of implementing intelligent transport systems in Europe, COM (2008)886, which was reflected in the 2010/40/EU directive of the European Parliament and Council of 7 July 2010 [2], on the framework of implementing intelligent transport systems in the area of the road transport and interfaces with other types of transport.

The 2010/40/ EU Directive establishes frameworks supporting coordinated and coherent implementation and application of intelligent transport systems (ITS) within the area of the European Union, especially in the trans-boarder context between the member states, as well as defines the necessary, for this purpose, general conditions.

The Directive concerns ITS applications and services in the area of the road transport and their interfaces with other types of transport, without negatively affecting the issue of national security or those necessary for the national defence requirements.

As part of the priority areas the following issues represent key actions on development and application of specifications and standards:

- ensuring availability of the services, within the area of the entire EU, on the information about the travel using various types of transport (detailed data about the roads and traffic in the real time),

- data and procedures concerning providing - to the best of abilities - to the users free of charge the minimum range of the general information about the traffic and related to the road safety, 
- harmonised providing interoperable eCall service within the entire EU,

- ensuring information services and those about booking safe and secure parking spaces for the trucks and utility vehicles.

\section{European Commission's actions on the interoperability of the integrated ITS}

The European Commission says that ITS systems being implemented in the EU member states are not interoperable due to some reasons, for instance, discrepancies in the interpretation of legal regulations, technology standards (specifications) and lack of cooperation capability.

Interoperability means the ability of the system to safely and without interruptions transfer data, which can reach certain size required for a given network, determined in the standards. Interoperability of ITS within the European Union should be ensured at the technical, conventional and procedural level, assuming that there have been actions designated for the European Union, aimed at achieving it, and which are conducted both in the form of joint undertakings, and independent actions of the individual member states.

In accordance with the document - (EIF) European Interoperability Framework, it is possible to select technical, semantic and organisational interoperability. Technical interoperability covers technical issues, interconnections of computer systems and services. The semantic interoperability guarantees, that the exact meaning of the information being exchanged is understood by every other application, which was not initially prepared for this purpose. Organisational interoperability refers to the defining of the business processes and initiating cooperation between the administrative bodies, which are willing to exchange information, and be characterised by different internal structures and processes.

Due to the problems concerning interoperability of ITS, the European Commission developed a mandate $\mathrm{M} / 453$ and invited European standardisation organisations: CEN, CENELEC, ETSI and ISO to prepare harmonised standards in the area of implementation of the integrated ITS.

The integrated ITS represent systems relying on the following types of communication: V2V (vehicle-to-vehicle), V2I (vehicle-to-infrastructure), I2V (infrastructure - to - vehicle), I2I (infrastructure - to - infrastructure).

At the highest level, the agreement was signed between the European Commission and a US Department of Transport on 9 November 2010 and the Communications Ministry of Japan.

The standardising institutions are to develop specifications and guidelines in order to support and implement wide application of the integrated ITS at the level of the European Union. CEN and ETSI formally accepted the mandate, while CENELEC will not participate in the development of the standards in mentioned mandate. On behalf of CEN, in the development of standards, will take part the Technical Committee TC278, which will cooperate with TC 204 (Tab. 1).

CEN and ETSI will develop standards (EN) technical specifications and guidelines in the field of communication and information as part of ITS, as far as it is possible within 30 months, required by the power of attorney (from 15.01.2010 till 15.07.2012).

The technical specifications require conformity and interoperability tests, which need time and vast resources of experts from the EU firms as well as domestic standardising institutions.

The mandate's aim is to define the list of minimum standards for the interoperability and other certain technical specifications in order to support ITS services.

Program defines also an agreed division of responsibility between CEN and ETSI (Tab. 2), and detailed description of the current co-operation. For this purpose the ITS Control Group has been established, which will monitor the activities.

CEN and ETSI will deal with adapting the ISO standards (Tab. 3), for the needs of the EU. CEN is responsible for the physical layer, network layer (traffic management) in accordance with the OSI model. ETSI answers for the communication architecture, transport and application layer (V2V), network layer, media, data management, data security, confirming interoperability tests. 
Tab. 1. Areas of TC 278 and TC 204 activity as part of the integrated ITS [8]

\begin{tabular}{|l|c|c|}
\hline Area of activity & CEN/TC 278 & ISO/TC 204 \\
\hline Electronic road fare collection (EFC) & WG 1 & WG 5 \\
\hline Fleet and freight management systems (FFMS) & WG 2 & WG 7 \\
\hline Public Transport (PT ) & WG 3 & WG 8 \\
\hline ITS data bases & WG 4 3 & WG 10 \\
\hline Traffic \& Traveller Information (TTI) & WG 8 & WG 9 \\
\hline Road Traffic Data (RTD) & WG 10 & \\
\hline HMI Interfaces & & WG 11 \\
\hline Navigational systems & WG 12 & WG 4 \\
\hline Automatic vehicle identification and devices (AVI/AEI) & WG 13 & WG 1 \\
\hline Architecture and terminology & WG 14 & WG 14 \\
\hline Stolen vehicles recovery systems & & WG 15 16 \\
\hline Warning and control systems & & WG 17 \\
\hline eSafety/eCall & & WG 18 \\
\hline WAN Systems (protocols and interfaces) & WG 16 & \\
\hline Intermodal systems (ITS applications) & & \\
\hline Integrated ITS & & \\
\hline
\end{tabular}

Tab. 2. Distribution of the responsibility between CEN and ETSI in accordance with the Mandate M/453

\begin{tabular}{|l|l|c|c|c|}
\hline \multicolumn{1}{|c|}{ Standard } & \multicolumn{1}{|c|}{ Description } & $\begin{array}{c}\text { Respons. } \\
\text { body }\end{array}$ & $\begin{array}{c}\text { CEN/TC278 } \\
\text { WG }\end{array}$ & $\begin{array}{c}\text { ISO/TC204 } \\
\text { WG }\end{array}$ \\
\hline $\begin{array}{l}\text { Definitions, } \\
\text { harmonised } \\
\text { technology. }\end{array}$ & $\begin{array}{l}\text { Common understanding, as far as } \\
\text { definitions and technologies used } \\
\text { in the standardisation. }\end{array}$ & CEN & $\begin{array}{c}1,3,4,8,12, \\
13,14,15,16\end{array}$ & $\begin{array}{c}1,3,4,5,7,8,9, \\
10,14,16,17, \\
18\end{array}$ \\
\hline $\begin{array}{l}\text { ITS } \\
\begin{array}{l}\text { communication } \\
\text { architecture. }\end{array}\end{array}$ & $\begin{array}{l}\text { Communication architecture for } \\
\text { the integrated ITS. Applications } \\
\text { and communication means (OSI). }\end{array}$ & ETSI & 13,16 & $1,16,17,18$ \\
\hline
\end{tabular}

Tab. 3. Standards developed by CEN and ETSI

\begin{tabular}{|l|l|}
\hline Physical layer & $\begin{array}{l}\text { ISO 14813-1 (2007); ISO 14813-5 (2010); EN/ISO 17573, ISO/TR 24529 } \\
\text { (2008), ISO TR26999 (2011) }\end{array}$ \\
\hline Transport layer & ISO TS 26683-1; ISO 15638-1 \\
\hline Simulation methods & ISO 16786 \\
\hline Terminology & ISO TR 17465 \\
\hline On-board devices & ISO 15622, ISO 26684 \\
\hline HMI Interfaces & EN ISO 15005 \\
\hline $\begin{array}{l}\text { Communication } \\
\text { architecture }\end{array}$ & $\begin{array}{l}\text { ISO 21217; ETSI: ES } 202663, \text { TS } 102 \text { 637, TS } 102638, \text { TS } 102636, \text { TS } 102 \\
\text { 665 }\end{array}$ \\
\hline
\end{tabular}

CEN and ETSI will provide and open website with the information on the standardisation work on the current information about the progress of the standardisation work in order to enable the interested parties to monitor the activities and planned coordination between the standardising organisations.

Some of the standards have already been adapted, e.g. EN/ISO 17573, EN ISO 17575, EN ISO 12855, while ISO 21217 standard has been accepted for the EU as ETSI EN 302665 (Fig. 2). 


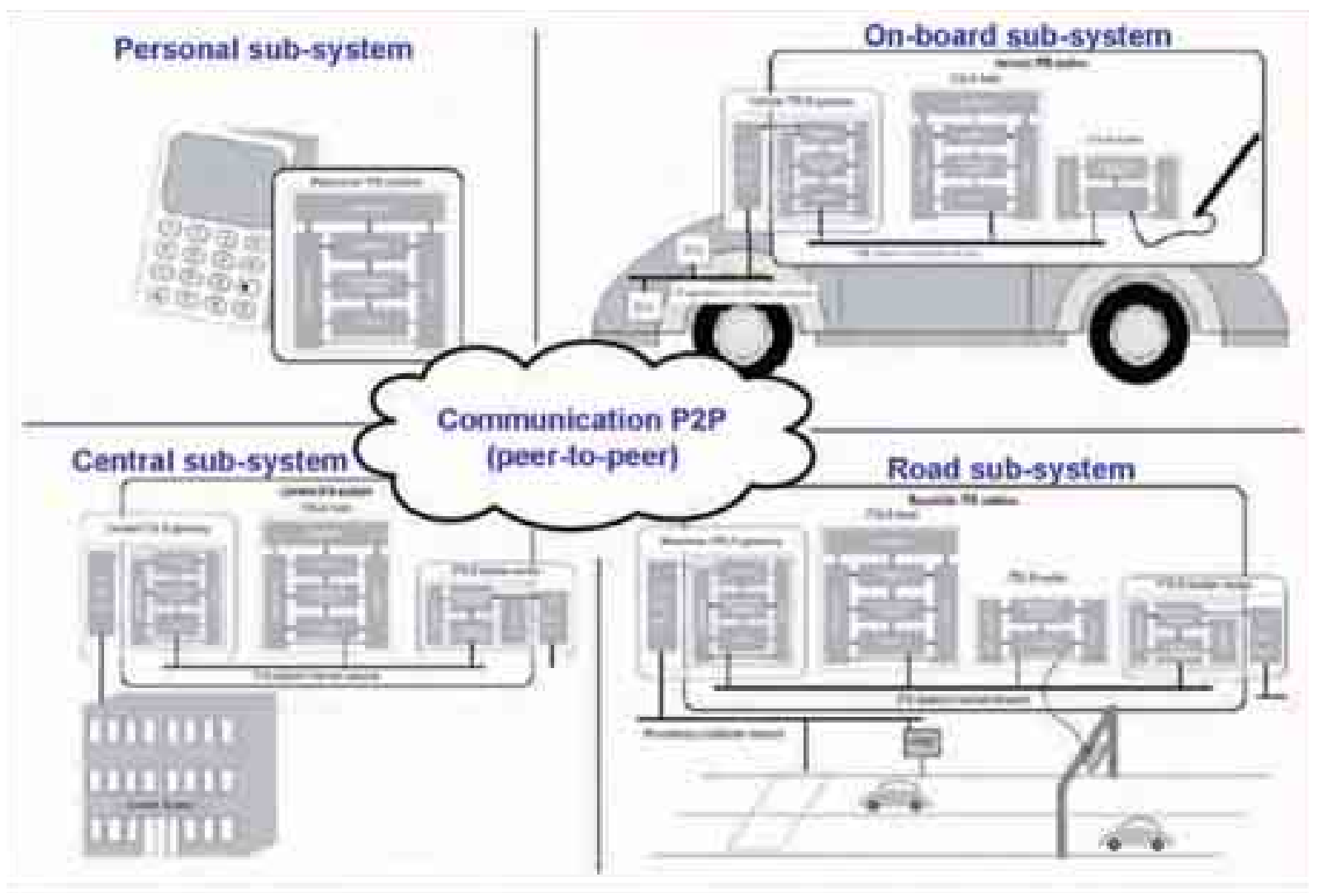

Fig. 2. ITS communication architecture [9]

In accordance with the 302665 standard, the ITS integrated communication architecture has been defined, which encompasses:

- Personal sub-system (handy mobile devices, such as mobile phones),

- Central sub-system (central part of the system: host, gateway, router),

- On-board sub-system (devices in the passenger cars and trucks),

- Road sub-system (gates, information boards, etc.).

The standard contains also basic data concerning advanced communication technologies, communication protocols and management functions. The communication is to relay on the P2P (peer-to-peer) technology, which means, that every user (host) has the same authorisations and possibility of initiating and receiving calls, plays the role of a server and a client, that is collects data and makes its own resources available to the other users. The systems equipped with the central server are much more effective, because the new user connecting up to the network receives, on the start, a list of all users connected to the same server and has an access to the index of the files available. The EC made a decision with respect to harmonised usage of the communication $5.9 \mathrm{GHz}$ frequency in the EU. This is aimed at obtaining significant improvement of safety efficiency of the road traffic in Europe, among the others by potential reduction of the dangerous situations on the roads and the number of road accidents, fatalities and injuries.

\section{Motor Transport Institute's actions on implementation of the integrated ITS}

In Poland, in comparison to other European countries there are serious delays in the process of implementing intelligent transport systems, and already implemented traffic management systems in some cities, are not interoperable, which effectively means that they can not co-operate with each other due to the lack of possibility to exchange data.

It appears that the existing lack of standardisation of the telematic devices in the Polish road engineering negatively affects the development in this area, and real problems may only become 
apparent in the nearby future. At present, it is only the beginning of the computerisation of the Polish roads. Construction expenditures are decentralised and are only of a local character. Saturation of the Polish roads with the telematic devices, with an exception of some cases, is low, while the example of the European countries of immeasurably higher development of the road infrastructure than in Poland, shows the direction of its further development, fit for the XXI century. Everything should strive towards centralisation - linking local systems into a global management system, for the entire country, or at least into the traffic monitoring. This may cause additional investments into a local infrastructure, in order to unify types of the devices or even complete replacement of the devices, which are incompatible with ,the world". For this reason the people and institutions making a choice of the devices (manufacturers) for their road systems, should pay particular attention also on this aspect. It is necessary to demand the highest possible class of the standardising requirements.

The ideal solution to the problem would be to create country-wide planning documents concerning the implementation of the ITS architecture, and also specification for applications and ITS services, as far as functional requirements are concerned which would cover widest possible variety of the telematic devices, but conforming to the EU and Polish standards. Making it a Polish standard would finally solve many problems.

Motor Transport Institute has run two research projects on the implementation of the intelligent transport systems.

From June 2008, until November 2010 the Institute ran the project - „Functional structure of the National Automatic Toll Collection System for the use of motorways and expressways".

The effectiveness of the vehicle recognition (ANPR and DSRC) was 99,9\%. Data from PDOP was $90 \%$ of the ideal values (below 1) and $8 \%$ of the superb ones (below 3). During the positioning in the GPS system there were from 5 to 11 available satellites, which covered $99 \%$ of all measurements.

In the course of the tests, the system recognised Swiss on-board device Tripon EU, French Passango of the DSRC type and the German - Toll Collect of the GPS/GSM type. The proposed by Motor Transport Institute and FELA firm, AutoGuard solution, meets the conditions for the hybrid system.

The system is interoperable, and can co-operate with GPS/GSM type systems (e.g. implemented in Germany and Slovakia), and also DSRC systems (implemented in Austria, Czech Rep., Spain, France and Italy).

From 1.12.2009 until 31.12.2011, the Institute ran the project: „Developing methodology of evaluating automatic eCall system of notification about the road accidents". The objective of the project was to develop methodology of evaluating automatic eCall system of notification about the road accidents. As part of the project, the following tasks have been completed:

1) Two laboratory stands have been developed for testing on-board eCall device. One of them makes it possible to run tests of the on-board eCall device in the high acceleration conditions of the values close to those taking place during the vehicle collision. Second stand is used for replicating voltage signal from the accelerometer, based on the measured data from the collision tests. These signals, replicated during tests signals from a real accelerometer, enabled to learn the collision detection algorithm characteristics implemented in the mass-produced air-bags controller.

2) The constructed test stands have been verified for the formal and legal requirements concerning eCall devices and adjusted to the current legal regulations in this area. It was necessary due to the last stage of the legislative work currently under way at the European Union level.

3) The eCall device simulator constructed consists of: collision detection module, teletransmission module and GPS receiver to establish current geographical position of the vehicle. 
4) The transmitter-receiver module has been developed, which with it's functionality corresponds to the devices that will be installed in the Emergency Notification Centres.

5) The eCall device simulator tests have been conducted in the real conditions. The tests were attended by the representatives of the emergency services. To make contact between the devices the public mobile phone network was used, maintaining the same conditions in which the real transmitter-receiver module of the eCall devices will function.

6) The methodology of evaluating eCall device has been developed taking into account such aspects of its functioning as correctness of the collision detection and making connection between the on-board eCall device and CPR, with maintained procedures and times defined in the standard developed by 3 GPP.

In accordance with the decision of the European Commission [1], each member state is obliged to produce the report, by the 27 of August 2012, which ought to contain general data on the planned actions during the next five years and concerning the implementation of ITS, including the following issues:

- a description of the national approach and/or strategy on the development and deployment of ITS, including its main objectives,

- a description of the technical and legal framework applicable to the development and deployment of ITS,

- a description of the ITS deployment activities,

- a description of the national priority areas for actions and related measures, including an indication of how these are related to the priority areas laid down in Article 2 of Directive 2010/40/EU,

- the implementation of current and planned actions covering: instruments, resources, consultation and active stakeholders, milestones, monitoring.

For this reason, the consortium has been formed comprising three research institutes (Motor transport Institute - consortium leader, National Institute of Telecommunications, Road and Bridge Research Institute). These institutes possess both experience and expert knowledge in conducting scientific research and development work in the field of the transport management, transport telematics (telecommunication and tele-information technology) and road infrastructure. They conduct activities of an interdisciplinary character related to legislation and standardisation of the transport telematics, economics, IT society development and training services. The consortium intends to run the project: National architecture of the intelligent transport systems. As part of the project there will be following tasks carried out:

- developing tools necessary to conduct the project tasks, ensuring the fulfilment of the tasks and tests,

- identification of the domestic systems and ITS devices as well as the needs of the users and stakeholders,

- developing model of the national ITS architecture, determining tasks and objectives for the individual bodies of the state and local administration as well as the private sector,

- developing organisational and technical solutions for the ITS sub-systems,

- developing program of the ITS implementation in Poland taking account the legislative and social conditions,

- developing national database of the technical specifications, standards and requirements for the ITS systems and devices, to make it generally available to the users as a support in creating technical specifications of the designed telematic systems.

Ministry of Administration and Digitalisation supported the motion concerning running of the aforementioned project on the 26 January 2012. The results of the project will be used by the department, mainly during the implementation of the State Computerisation Plan, and also in the legislation work associated with this process. 


\section{Conclusions}

ITS applications affect the smooth flow of traffic, solve problems of automatic toll collection for the use of roads, enable automatic control of the vehicles speed, dynamic adaptation of the speed limits in force to the current driving conditions, dynamic measurement of the vehicles weight, and also data transfer about the road conditions, or even a number of the free parking spaces. Moreover they facilitate solving problems associated with the road repairs, or planned changes in the traffic organisation.

Implementation of the autonomous ITS in the European states and the lack of possibility of co-operation between the systems caused, that the European Commission conducts wide-spread actions on the interoperability of ITS.

At present in Poland, the ITS applications are sporadically used for more effective vehicles fleet management and controlling road traffic, more so, the already implemented systems in some cities are not interoperable. The essential obstacles for building ITS in the Polish cities are:

- lack of the domestic ITS architecture (among the others - functional structure of the system),

- lack of the information exchange standards between the system's devices,

- lack of the strong experts, technical and financial support.

The worrying example is implementation in Poland of the road toll collection system of obsolete DSRC type technology. By the October 2012, all member states ought to have implemented interoperable road toll collection systems, which mean that the driver with one OBU should be able to move freely over the entire EU area. The on-board unit of the Via Toll system, is not interoperable, and can only be used in the system within the Republic of Poland. The drivers heading to other EU countries will have to install even several devices to use the road infrastructure. The on-board Via box unit used in Poland manufactured by Kapsch, is not interoperable even with a similar Premid unit, also manufactured by Kapsch, and used in the Czech Rep.

The serious problem in Poland will be implementation of the pan-European eCall system, whose operation relies on using the emergency 112 number. In accordance with the latest EC decision, the introduction of eCall, as a standard equipment of all type approved vehicles is envisaged within the EU from the 1 January 2015. The common European 112 emergency number is already fully operational in $26 \mathrm{EU}$ member states (Bulgaria joined on 03.10.2011), and only in Poland there are still problems with it. The obligation of activating emergency 112 number is imposed on the EU states by the $2002 / 22 / \mathrm{CE}$ directive. According to the report of the Supreme Audit Office from 2010 and 2011 [6], the current system of answering calls to the 112 number is ineffective. The calls from the stationary phones to the 112 number are answered by 331 National Fire Service units, while the calls from the mobile phones are answered by 458 Police units. A good example is Małopolski District, where for the last two years the emergency 112 number has been functioning together with the Emergency Notification Centre in Cracow. As the first in Poland, the Cracow centre has the ability to locate the stationary and mobile phones, and from 11 February 2012, the Emergency Notification Centre in Poznan has been operational.

The challenges shown, concerning the ITS implementation in Poland and fulfilling the provisions resulting both from the 2010/40/EU directive, and also from the European Commission's 2011/453/EU decision, become a very serious problem for Poland.

Running of the project: „Domestic architecture of the European Commission” by three research institutes will contribute to solving the above problem by developing domestic architecture and operational program of the implementation of the European Commission in Poland.

\section{References}

[1] Commission Implementing Decision 2011/453/EU of 13 July 2011 adopting guidelines for reporting by the Member States under Directive 2010/40/EU of the European Parliament and of the Council (notified under document C2011/4947). OJ of the EU, L 193/48, 49 of 23/7/2011. 
[2] Directive 2010/40/EU of the European Parliament and of the Council of 7 July 2010 on the framework for the deployment of Intelligent Transport Systems in the field of road transport and for interfaces with other modes of transport. OJ of EU, L $207,06 / 08 / 2010$ P. $0001-0013$.

[3] Directive 2002/22/WE of the European Parliament and of the Council of 7 March 2002 on universal service and users' rights relating to electronic communications networks and services (Universal Service Directive)on the common. OJ of The UE, L 2002.108.51.

[4] M/453 EN. Standardization mandate addressed to CEN, CENELEC and ETSI in the field of information and communication technologies to support the interoperability of co-operative systems for Intelligent Transport in the European Community, DG ENTR/D4, Brussels 4.10.2009.

[5] Report of accidents, Care \& national data, European Commission, 15.05.2011.

[6] NIK Report, Information of functioning emergency No 112 at Poland teritory, Warsaw 2011.

[7] Njord, J., Peters, J., Freitas, M., Warner, B., Allred, C., Bertini, R., Bryant, R., Callan, R., Knopp, M., Knowlton, L., Lopez, C., Warne, T., Safety Applications of Intelligent Transportation Systemsin Europe and Japan. Report FHWA-PL-06-001, January 2006.

[8] Schade, H. J., The Mandate on Co-operative ITS and the ITS Directive, CEN. 3rd ETSI TC ITS Workshop, Venice 2011.

[9] Standard ETSI EN 302 665, ITS: Communication architecture. ETSI, Sophia Antipolis Cedex - France 2010.

[10] Symon, E., Prophylactic and Analyze Group of BRD KGP, Warsaw 2012. 